\title{
Um olhar sobre a evolução histórica dos Estudos da Interpretação no Brasil
}

\author{
Christiano Sanches do Valle Silva*
}

\section{Introdução}

O objetivo deste trabalho é oferecer um olhar atualizado sobre a evolução dos Estudos da Interpretação (EI) no Brasil em perspectiva com os acontecimentos mundiais na área. Para tal, é necessário partir de um olhar global, entendendo o desenvolvimento e crescimento da área de EI de forma geral, para que então possamos nos concentrar nos acontecimentos em terras brasileiras. A natureza deste artigo nos permite oferecer uma visão sucinta dos fatos, que poderão ser aprofundados pelos interessados através das leituras listadas na bibliografia.

Este trabalho não poderia deixar de levar em consideração a importante contribuição de autores dos Estudos da Tradução (ET) na abordagem aqui utilizada. Assim, publicações de autores como Susan Bassnett (2014), André Lefevere (1990) e Mary Snell-Hornby (2006), os quais abordam o nascimento e a evolução dos Estudos da Tradução, serviram de motivação e ponto de partida para sua elaboração.

Entretanto, uma vez que trataremos aqui dos Estudos da Interpretação, ainda que como subárea dos ET, vão nos servir de referência autores mais diretamente associados aos EI, tais como Daniel Gile (1995, 2000, 2011) e Franz Pöchhacker (2002, 2004), entre os estrangeiros, e Reynaldo Pagura (2010), Branca Vianna (2015), Patrizia Cavallo (2016) e Denise Araújo (2017), dentre aqueles estabelecidos no Brasil, para

\footnotetext{
* Pontifícia Universidade Católica do Rio de Janeiro (PUC-Rio).
} 
mencionarmos apenas alguns dos pesquisadores na área que nortearam a produção deste texto.

Na passagem entre a visão do contexto global dos EI e a visão do contexto brasileiro, julgamos interessante a inclusão de uma perspectiva não ocidental para ajudar a contextualizar melhor o posicionamento do Brasil no universo dos EI, com destaque para a contribuição de Ziyun Xu (2014). A perspectiva não ocidental não foi selecionada ao acaso, mas com a intenção de incluir um termo de comparação mais próximo à realidade econômica brasileira, sendo a China, país que se destaca em nossa abordagem, membro dos BRICS (Brasil, Rússia, Índia, China e África do Sul). Assim, evitamos comparar o Brasil somente aos países da Europa e da América do Norte, de perfil econômico diferenciado e mais tradicionalmente produtores de literatura em tradução e interpretação.

Cabe ressalvar que este artigo não pretende cobrir a totalidade das produções acadêmicas ou de natureza científica sobre a interpretação, assim como não contemplará de forma detalhada algumas modalidades de interpretação, como a comunitária e a de língua de sinais. Estas apresentam percursos de desenvolvimento intimamente associados à evolução dos estudos sobre interpretação de conferências, mas bastante diferenciados devido a questões de sua própria natureza e de contexto regulatório diferenciado, como é o caso da interpretação em língua de sinais no Brasil. Assim, a maior parte das informações estará relacionada ao que convencionou-se chamar de interpretação de conferências, abrangendo tanto a modalidade consecutiva (sem uso de equipamento e em turnos alternados de fala) e a modalidade simultânea (na qual os intérpretes realizam sua tarefa ao mesmo tempo em que o orador profere seu discurso, com uso de equipamentos de transmissão). Além disso, a interpretação será aqui diferenciada da tradução de textos escritos, referida apenas como tradução. Adotando a definição usada por Pöchhacker (2004, p. 11) e desenvolvida com base no trabalho de Otto Kade (1968 apud PÖCHHACKER 2004, p. 10), entendemos a interpretação em suas diferentes modalidades como uma forma de tradução na qual uma comunicação em outro idioma é produzida uma única vez e traduzida/interpretada para uso imediato pelas partes envolvidas no ato comunicativo. O uso do termo "comunicação", em vez de 
"elocução", é proposital e visa a inclusão de formas não orais-auditivas de comunicação que fazem extenso uso de interpretação, como é o caso da interpretação em língua de sinais. Conforme afirma Pöchhacker (2004, p. 11), o estudo da interpretação não necessariamente pressupõe levar em consideração a tradução em todas as suas variantes e ramificações, entretanto, a escolha de definir a interpretação como uma forma de tradução evidencia o fato de que nenhum estudioso de interpretação pode ficar indiferente às contribuições teórico-conceituais dos Estudos da Tradução.

Prestados os esclarecimentos acima, vejamos então como se iniciaram os Estudos da Interpretação.

\section{Os Estudos da Interpretação: visão global}

Nunca é demais lembrarmos que a atividade de interpretar era amplamente presente na Antiguidade, com registros de sua existência datando de três mil anos antes de Cristo. Sua aplicação se dava numa variedade de contextos, tanto intersociais (relações entre diferentes culturas e sociedades) quanto intrassociais (inserção numa determinada comunidade). Nesse âmbito, sua prática era, inevitavelmente, mais próxima do que ficou conhecido, bem mais tarde, como interpretação em modalidade consecutiva, ou em contextos de interpretação comunitária.

Foi o advento da interpretação em modalidade simultânea, que ganhou importância com a política de igualdade linguística da União Europeia e notoriedade com seu uso em instituições internacionais de grande abrangência (OIT, ONU, EU, etc.), que serviu de disparador inicial de todo um movimento de profissionalização dos intérpretes e, consequentemente, de estímulo ao estudo dessa atividade amplamente difundida durante os Julgamentos de Nuremberg, ao final da Segunda Grande Guerra.

Como afirma Pöchhacker (2004), o movimento de profissionalização dos intérpretes desempenhou um papel fundamental no surgimento de um campo de estudos (p. 27). Para o autor, o exemplo excepcional de Paul Mantoux interpretando para os Aliados na Conferência de Paz de Paris, em 1919, representou um ponto de inflexão na história moderna da 
interpretação em nível internacional, marcando a diferença entre intérpretes ad hoc e intérpretes profissionais, com formação específica.

Foi justamente no contexto de atuação de equipes treinadas de intérpretes na Liga das Nações (anos 1920-30) que surgiram as primeiras iniciativas de formação de intérpretes, à época, com foco no ensino de técnicas de anotação para consecutiva. Estão associadas a esse contexto as primeiras produções de pesquisa científica sobre a interpretação e os intérpretes, ainda antes dos acontecimentos de Nuremberg que impulsionaram a atividade.

É importante ainda levar em consideração a fundação de associações profissionais, como a AIIC (Associação Internacional de Intérpretes de Conferência), fundada em 1953, com importante papel desempenhado na definição de melhores práticas, tanto no que tange à atuação profissional, quanto no que diz respeito à formação dos intérpretes. Suas diretrizes em termos de formação serviram de referência para as instituições que surgiram nos anos 1950 e 60, sendo até hoje importantes no setor (PÖCHHACKER, 2004; ARAÚJO, 2017; VIANNA, 2015).

Daniel Gile (2000) adota uma divisão da evolução dos Estudos da Interpretação em quatro períodos: o primeiro dos quais, nos anos 1950 e início dos anos 1960, seria um período pré-pesquisa, com trabalhos sobre os princípios e processos subjacentes à interpretação produzidos por intérpretes praticantes, com caráter mais prescritivo. Nessas décadas, surgiram os primeiros livros dedicados à interpretação (Jean Herbert, 1952; Jean-François Rozan, 1956; Henri van Hoof, 1962; Danica Seleskovitch, 1968) e os primeiros programas de formação de intérpretes de conferência, ainda com foco profissionalizante, em oposição ao acadêmico (PÖCHHACKER, 2004). Destaca-se no período a publicação por Danica Seleskovitch, em 1962, de sua obra L'interprète dans les conférences internationales, na qual apresentava todo o embasamento conceitual que moldou o ensino de intepretação na ESIT (École Supérieure d'Interprètes et de Traducteurs), mais célebre representante das escolas de interpretação francesas.

O segundo período, nos anos 1960 e início dos anos 1970, seria a fase da Psicologia Experimental, com uma exploração preliminar da interpretação por psicólogos e psicolinguistas, que aplicavam os paradigmas 
de suas disciplinas ao estudo da interpretação (GILE, 2000). Foi quando David Gerver, maior representante do movimento de pesquisas psicológicas sobre a interpretação, defendeu sua tese de doutorado na Universidade de Oxford, Inglaterra, abordando elementos de ordem mais técnica e sua interferência no desempenho dos intérpretes. Uma característica desse período é justamente a tentativa de conferir aos EI um caráter mais científico, com base experimental, voltado não para o treinamento de intérpretes, mas para o conhecimento do processo da interpretação em si, especialmente em relação a fatores cognitivos.

Ao mesmo tempo em que os psicólogos descobriam a interpretação como objeto de estudos, alguns intérpretes praticantes com pendor acadêmico começaram também a produzir pesquisa. Foi o caso de Otto Kade, cuja tese de doutorado de 1964 estabeleceu os fundamentos teóricoconceituais para o estudo sistemático da tradução e da interpretação (PÖCHHACKER, 2004, p. 34), sendo o maior representante da Escola de Leipzig, ligada à universidade de mesmo nome.

Outras Escolas também marcaram o período com suas produções, como a Escola Soviética, representada por Ghelly V. Chernov e o Instituto de Línguas Estrangeiras Maurice Thorez de Moscou. O trabalho de Chernov se destaca por ser o mais influente na literatura russa sobre interpretação (PÖCHHACKER, 2004, p. 35).

Na capital francesa, Danica Seleskovitch estava à frente da Escola de Paris, tendo sido a responsável pela inserção da pesquisa em interpretação no universo da Sorbonne, através da ESIT, fundada em 1957 e depois vinculada à Université Sorbonne Nouvelle - Paris 3, da qual foi diretora entre 1982 e 1990 e cujo o nome cunhou, e da criação de um programa de doutorado em Estudos da Tradução e da Interpretação (Traductologie, no original em francês) na mesma instituição. Programa do qual surgiram teses de doutorado importantes para a área, revelando autores como Karla Déjean le Féal, Mariano Garcia-Landa e Marianne Lederer.

O terceiro período, do início dos anos 1970 até meados dos anos 1980, seria o período dos Praticantes, com uma predominância de trabalhos e pesquisas realizados por intérpretes-pesquisadores. O período corresponde, justamente, a uma primeira onda de produções sobre o tema devido ao 
suporte de instituições de formação e ao crescente número de intérpretes formadores, o que coincidiu com uma diminuição do interesse por parte de psicólogos e psicolinguistas (GILE, 2000).

No quarto período, do final dos anos 1980 em diante, houve o que Gile chama de Período de Renovação da pesquisa em interpretação de conferências, com tentativas de realizar trabalhos de caráter mais científico e interdisciplinar. Foi justamente na segunda metade da década de 1980 que ocorreu a segunda onda, com um novo ímpeto à pesquisa em interpretação de conferências, inúmeros novos pesquisadores sendo atraídos pela área, somado a desenvolvimentos institucionais, como a criação de vários novos programas de formação de tradutores e intérpretes e a consequente produção de mais publicações (GILE, 2000, p. 4).

Este é o período que Pöchhacker (2004) denomina de Reorientação (p. 37). Apesar de a pesquisa na área ignorar os desenvolvimentos que ocorriam em outros setores, como na interpretação comunitária e na de língua de sinais, houve uma renovação interna e uma reorientação metodológica. Esse movimento pode ser ilustrado pelas dissertações de mestrado de Catherine Stenzl e Jennifer Macintosh, ambas concluídas em 1983 na Universidade de Londres, e diversos artigos de caráter inovador produzidos por Daniel Gile. Esse grupo de intérpretes-pesquisadores aprofundou o interesse por estudos mais científicos sobre a interpretação de conferências e mais teses de doutorado de cunho experimental foram publicadas. No ocidente, uma abordagem ancorada na psicologia cognitiva foi explorada em trabalhos de Sylvie Lambert e Barbara Moser-Mercer, reforçando a visão da interpretação como processamento de informações cognitivas. Foi ainda em 1985 que a revista Meta teve um número temático sobre interpretação de conferências publicado, ilustrando a renovação vivida pelos EI.

Mas não somente de publicações vivia o setor. Em 1986, a Universidade de Trieste organizou um simpósio internacional sobre formação em interpretação de conferências que se tornou um marco na área. Foi durante esse evento que diferentes pesquisadores colocaram em questão o modelo defendido pela Escola de Paris, em nome de uma estrutura mais rigorosa de pesquisa empírica. Houve quem chamasse o simpósio de "Início 
da Era de Trieste" (PÖCHHACKER, 2004, 38), e o fato é que a universidade acabaria por se tornar um influente centro de produção de pesquisas sobre interpretação de conferências nos anos que se seguiram. Contribuíram para isso sua abordagem interdisciplinar aos fundamentos neurolinguísticos da interpretação e o lançamento do informativo The Interpreter's Newsletter, que, devido ao seu sucesso e volume de publicações, acabou se tornando uma importante revista especializada na área.

Com a aposentadoria de Seleskovitch de suas atividades universitárias em 1990, ficou consolidada a transição de liderança no setor de Paris para Trieste. A renovação vivida pelo campo foi ao mesmo tempo vertical, com cada vez mais pesquisas empíricas explorando os processos cognitivos envolvidos na interpretação de conferências, e horizontal, com uma diversificação e abertura para além das conferências e organizações internacionais. Esse desenvolvimento horizontal de abertura e expansão pode ser ilustrado pela coletânea organizada por David e Margareta Bowen, da Georgetown University, Estados Unidos, que incluiu contribuições abordando temas diversos, entre os quais história da interpretação diplomática, formação em interpretação de conferências, temas relacionados à interpretação em tribunal, interpretação comunitária e interpretação em veículos de comunicação (PÖCHHACKER, 2004, 38-39).

Franz Pöchhacker (2004) identifica o Simpósio de Trieste como o evento que sinalizou a consolidação da interpretação como disciplina acadêmica. Seis anos depois do simpósio, surgiu o que o autor chamou de uma "oportunidade ideal para a comunidade de pesquisadores de interpretação de promover sua dupla pauta de aspiração à interdisciplinaridade e de assumir um lugar próprio na academia" (p. 39). Em setembro de 1992, foi organizado na Universidade de Viena o "Translation Studies Congress", que reuniu estudiosos tanto de tradução quanto de interpretação. O palestrante principal convidado a falar sobre interpretação na plenária foi Daniel Gile, que propunha "uma abertura a outras disciplinas do que ele chamou de estudos da 'interpretação'" (p. 39). Foi a primeira vez que o termo Estudos da Interpretação foi usado no ambiente acadêmico e, a partir daí, sua adoção por outros estudiosos da área foi naturalmente acontecendo. Pöchhacker chama a atenção para o fato de 
que a escolha do termo Estudos da Interpretação, cunhado com base no termo usado por James Holmes em 1972, "reforça a identidade dos estudos da interpretação como uma subárea no campo dos Estudos da Tradução" (p. 39).

\section{Perfil da produção científica nos EI}

Daniel Gile (2000) publicou um artigo com uma abordagem cientométrica, ou seja, de medição de produção científica nos EI. Seu levantamento cobre a literatura até dezembro de 1999, com base num banco de dados pessoal de pesquisa em interpretação de conferências (PIC). Segundo o levantamento, a produção da PIC é altamente diversificada, incluindo temas considerados não científicos, como condições de trabalho, questões profissionais, ensaios, manuais, etc. Cerca de dois mil textos foram considerados no levantamento, constituindo um corpus que também incluiu entradas como interpretação em tribunais e em língua de sinais que abordam questões técnicas, cognitivas e linguísticas pertinentes para a interpretação de conferências. Foram excluídos resultados relacionados à interpretação comunitária e interpretação em tribunais que cobriam questões sociológicas, o que limita o levantamento realizado por Gile em termos de sua representatividade para o campo dos Estudos da Interpretação como um todo. Sua abordagem foi orientada por uma busca por trabalhos de natureza empírica. A produção científica na área foi subdividida pelo autor em diferentes categorias, como dissertações, teses e monografias de graduação, por um lado, e artigos em coletâneas, por outro. No primeiro caso, a grande maioria dos trabalhos é produzida como requisito para obtenção de grau, sendo a Itália, a República Tcheca, a Alemanha e a Finlândia os países com maior produção. Vale destacar que a alta produtividade de países como Itália e República Tcheca está associada a uma atividade intensa de autores individuais, não determinando um índice de produção nacional. Outra informação pertinente é o fato de que entre os 244 autores de monografias, dissertações e teses cobertos pelo levantamento, apenas um possuía doutorado (p. 5).

Segundo Gile (2000), artigos publicados em coletâneas são menos significativos em termos de produção científica, uma vez que muitos não se enquadram na categoria de "científico" empregada pelo autor. Muitos são 
ensaios e textos prescritivos, outros são versões escritas de comunicações realizadas em conferências e seminários, "sem critérios de inovação e praticamente nenhuma seleção para inclusão nos anais" (p. 5). Para ele, "as coletâneas refletem a natureza não empírica da PIC" (p. 5).

$\mathrm{O}$ autor examinou ainda os temas abordados na pesquisa em interpretação de conferências (PIC), dividindo-os em: 1) formação, claramente o tema mais popular desde o início da PIC e, segundo o autor, tendo sua prevalência influenciada não somente pelo fato de muitos pesquisadores serem também formadores de intérpretes, mas por se tratar de textos que podem ser redigidos por pessoas sem treinamento ou habilidades em pesquisa, sendo basicamente de caráter descritivo, analítico ou prescritivo; 2) questões profissionais, como acesso à profissão, condições e ambiente de trabalho. Este tema está bastante presente na produção japonesa, influenciado por fatores econômicos e sociológicos; 3) questões de idioma, envolvendo proficiência, par linguístico e outros fatores linguísticos também são numerosos; 4) a formação em interpretação consecutiva é outro tema que surge, já não com tanta frequência, mas que demonstra que a modalidade simultânea de interpretação, apesar de sua hegemonia em eventos multilíngues, não tomou o mercado por completo, além de o domínio das técnicas de consecutiva ser considerado importante; 5) os fatores cognitivos ainda figuram como objeto de pesquisa, ainda que em proporção bem menor do que no Período da Psicologia Experimental, nos anos 1960 e 1970. Segundo Gile (2000), pode-se atribuir essa diminuição à falta de treinamento para pesquisa entre intérpretes-pesquisadores, além de problemas como o acesso difícil a sujeitos de pesquisa e material; 6) os estudos sobre a qualidade em interpretação assumiram outra roupagem, passando de produções mais prescritivas para estudos empíricos específicos desde meados dos anos 1980. Mais uma vez, segundo o autor, isto se dá, possivelmente, devido à possibilidade de se realizar pesquisa empírica sobre o tema sem necessidade de embasamento teórico complexo; 7) outras duas categorias de estudos aparecem no levantamento de Gile, os estudos neurofisiológicos da interpretação, um desenvolvimento recente e foco constante de pesquisas empíricas, porém conduzidos por poucos autores, e os estudos sobre interpretação para meios de comunicação, na esteira do 
desenvolvimento e globalização desses mesmos meios, que requerem cada vez mais o serviço de intérpretes.

Quanto aos autores da pesquisa sobre interpretação, Gile verificou que sua produtividade média permanece muito baixa, sendo que estes formam uma comunidade pequena de cerca de 500 estudiosos, após quase 40 anos de existência (à época do artigo) dessa área de pesquisas. Além disso, muitos publicam apenas um trabalho, sendo a comunidade de pesquisadores realmente ativos composta por menos de 50 autores (2000, p. $8)$.

Ao considerar os centros geográficos de produção, Gile verificou que houve mudança em termos de volume de produção ao longo dos anos. Alguns países, como Dinamarca, Israel e Espanha, apresentam uma produção pequena. A União Soviética, a Tchecoslováquia e a Alemanha eram os países mais produtivos no início. Apesar do crescimento da produção na Tchecoslováquia e na Alemanha, os dois países foram ultrapassados em volume de produção pela Itália, o mais produtivo ao longo dos anos 1990, pelo Japão, segundo país em produção, e pela Finlândia. De acordo com o autor, os números para França, Áustria e Estados Unidos são enganosos, pois derivam da produção de um ou dois autores especialmente prolíficos (2000, p. 9).

Para ele, três fatores qualitativos desempenharam um papel importante no desenvolvimento da Pesquisa em Interpretação de Conferências (PIC): o trabalho de algumas personalidades, fatores econômicos e fatores institucionais. Como personalidades, Gile menciona David Gerver, na fase Experimental dos estudos da interpretação, ainda muito citado e considerado pioneiro na área. Já na fase dos Praticantes, Danica Seleskovitch, da escola francesa ESIT, fundadora do primeiro e único doutorado francês em Estudos da Tradução, foi a autora mais produtiva e de maior repercussão. Mais recentemente, na fase de Renovação, sua presença foi enfraquecida, à medida em que o paradigma por ela proposto (a Teoria Interpretativa da Tradução) foi substituído por outro de cunho mais orientado para as ciências cognitivas de caráter empírico. Nos anos 1990, houve uma diluição e disseminação geográfica da produção de PIC. Ainda assim, alguns centros de pesquisa e autores se destacaram, tanto na 
Europa quanto no Japão. Outro importante acontecimento na área de PIC foi o lançamento da revista Interpreting por Barbara Moser-Mercer, juntamente com a abertura de um mestrado em formação de intérpretes na Suíça, atualmente no processo de organização do primeiro doutorado na área específica de Estudos da Interpretação. Moser-Mercer é considerada uma das lideranças em PIC, ainda que sua produtividade em termos de publicações não o reflita. Sua contribuição para a área, para a formação de intérpretes e para a produção e disseminação de pesquisas sobre o tema é inquestionável.

Quanto aos fatores econômicos, Gile menciona o fato de a maioria dos pesquisadores de interpretação também serem intérpretes, sendo que, "na maior parte dos países, a interpretação é mais lucrativa do que a pesquisa" (2000, p. 11). Alguns autores importantes na área, como o próprio Gile, Ingrid Kurz e Akira Mizuno, fazem pesquisa com seus próprios recursos, desvinculados de qualquer instituição e com financiamento próprio. A área de PIC é bastante circunscrita em termos de número de pesquisadores e poucos são os que produzem pesquisa continuamente.

Também institucionalmente os Estudos da Interpretação se diferenciam de áreas mais estabelecidas, com poucos departamentos de tradução e interpretação, até recentemente, ambas as disciplinas se localizando em departamentos de línguas ou em programas específicos de formação. Foi importante, nos anos 1970, a criação do primeiro programa de doutorado na ESIT, renomada escola francesa de interpretação, com um número relativamente grande de teses de doutorado sendo publicadas até o início dos anos 1980 (GILE, 2000, p. 12), conforme já mencionado anteriormente. Em anos posteriores, outros departamentos de tradução e interpretação, e até mesmo faculdades, foram criados em diferentes países, como Espanha, Áustria, Alemanha e Finlândia.

Com a institucionalização mais forte da PIC, seguiu-se o lançamento de novos periódicos específicos para o tema, como The Interpreter's Newletter de Trieste, em 1988, Interpreting Research no Japão, em 1991, e o periódico Interpreting, em 1996, publicado pela John Benjamins. No final dos anos 1980 e início dos anos 1990, a PIC foi fortemente influenciada pela fundação de organizações internacionais de promoção da pesquisa na área, 
como a Cátedra de Estudos da Tradução CE(T)RA, de onde saíram quatro das catorze teses de doutorado sobre interpretação publicadas na segunda metade dos anos 1990. Uma tendência visível na PIC é sua progressiva abertura para comunicação interna e externa e em direção à interdisciplinaridade. Desde o final dos anos 1980, observou-se um grande número de referências cruzadas entre centros e entre disciplinas. Somente em 1986, após o fracasso da sugestão apresentada no congresso de Veneza de 1977, pleiteando maior interdisciplinaridade nos EI, os estudos interdisciplinares começaram de fato a figurar nas pesquisas sobre interpretação, especialmente devido a contribuições baseadas no paradigma neurofisiológico.

Uma característica observada nos Estudos da Interpretação é a de que os intérpretes-pesquisadores tendem a se abrir para outras teorias de disciplinas adjacentes, mas o oposto não é verdadeiro, sendo que pesquisadores não intérpretes tendem a citar somente referências de suas próprias áreas, sem incorporar contribuições dos EI. Além disso, o número de pesquisadores não intérpretes com produção mais constante não tem aumentado ao longo dos anos, poucos estudos empíricos foram gerados com a importação de conceitos de outras disciplinas e até mesmo os paradigmas importados da psicologia cognitiva, mais em voga nos anos 1990, geraram um número reduzido de estudos empíricos (GILE, 2000, p. 14). Gile (2000) observa que os "estudos empíricos representam uma porcentagem pequena da produção total ao longo dos anos, refletindo a natureza não empírica da área" (p. 14). As teses de doutorado tendem a apresentar mais trabalhos de natureza empírica, sendo também contribuições originais.

Apesar de todas essas constatações, o autor salienta que o uso de análises quantitativas pode ser enganoso, especialmente numa área tão pequena quanto a dos Estudos da Interpretação, em que, devido ao baixo número de autores, a produção elevada de uns poucos pode gerar distorções na comparação entre países e regiões. Mais estudos desse gênero, combinados a análises qualitativas, seriam necessários para se obter uma imagem mais clara da pesquisa em interpretação de conferências e sua comunidade. 
Ao analisar a situação dos Estudos da Interpretação na virada para o século XXI, Pöchhacker (2004), por sua vez, adota uma visão otimista, enxergando seu desenvolvimento como uma "história de sucesso" (p. 43). Ele concorda com a posição de Gile, ao afirmar que a comunidade de pesquisadores na área é pequena e que sua produtividade, ainda que constante, permanece baixa. Apesar disso, e de reconhecer que os EI estão sujeitos a múltiplas influências geradas por seu caráter interdisciplinar e pela natureza multifacetada de seu objeto de estudos, assim como se observa nos Estudos da Tradução, existiria uma ambiente favorável para os EI, já respeitados como uma subárea dos ET e reconhecidos por autores da envergadura de Venuti (2000 apud PÖCHHACKER, 2004) como uma área cujo "volume e grau de especialização exigem uma abordagem separada" (p. 44). Além disso, cada vez mais estudiosos da área com histórico em interpretação de conferências têm se interessado por pesquisas em contextos comunitários e os desenvolvimentos tecnológicos que têm impacto na profissão de intérprete são cada vez mais um objeto privilegiado de estudo.

Pöchhacker (2004) observa ainda que a disciplina possui suas próprias revistas especializadas e algumas obras de construção de identidade, como o The Interpreting Studies Reader (Pöchhacker \& Schlesinger, 2002, Routledge), o próprio livro Introducing Interpreting Studies (Pöchhacker, 2004, Routledge) e, mais recentemente, o Routledge Handbook of Interpreting (Mikkelson \& Jourdenais, 2015, Routledge).

\section{Uma visão não ocidental dos Estudos da Interpretação}

Durante suas pesquisas, tanto Pöchhacker (2004) quanto Gile (2000) mencionaram alguns avanços nos Estudos da Interpretação no Oriente. De forma a não deixar a abordagem deste trabalho circunscrita somente aos centros de pesquisa europeus e americanos, julgamos que seria interessante fazer uma brevíssima incursão em territórios mais a leste.

Evidentemente, e mais ainda num mundo cada vez mais globalizado e dispondo de tecnologias variadas de informação e comunicação, as teorias e conceitos produzidos em um centro geográfico de pesquisas se dispersam e atingem regiões as mais diversas ao redor do globo. Isso é ainda mais verdadeiro no ambiente institucional acadêmico, onde redes de colaboração 
são estabelecidas entre universidades, departamentos e entre os próprios estudiosos de determinado tema.

Assim, com a expansão dos centros de formação em interpretação de conferências na Espanha e a organização de eventos acadêmicos no mesmo país relacionados ao tema, o que se observou foi um número cada vez maior de contribuições oriundas de países da Europa Oriental, mas também de países como a China, que tem despontado como um forte centro de produção de pesquisas e publicações na área de tradução e interpretação.

Já em 1998, numa conferência organizada na Universidade de Vigo na qual a pesquisa em interpretação desfrutou de grande visibilidade, ficou evidenciado o momento de impulsão vivido pelos EI no Oriente, especialmente ilustrado pela presença de pesquisadores oriundos de Guangdong, Hong Kong e Taipei, na China.

Várias universidades chinesas têm organizado eventos sobre tradução e interpretação, com um crescente número de teses de doutorado publicadas no país após a expansão do número de programas de pósgraduação. Associações profissionais também desempenham um importante papel na difusão de publicações em revistas especializadas e já se espera que em breve surjam coletâneas e obras para organizar tal volume de produção.

O mesmo pode ser dito a respeito de publicações na Coreia, também como resultado da forte promoção de formação e pesquisa em tradução e interpretação. A Sociedade Coreana de Interpretação de Conferências, fundada por Jungwha Choi, começou a publicar em 1999 o periódico Conference Interpretation and Translation, incluindo, desde o início, contribuições de autores ocidentais. O mesmo Choi juntou-se com Marianne Lederer no lançamento do periódico sobre interpretação e tradução Forum, publicado em francês e inglês pela editora Presses de la Sorbonne Nouvelle. Para Pöchhacker (2004), nota-se aí o crescimento dos EI em nações do Oriente e sua atuação num âmbito cada vez mais internacional.

O caso da China é emblemático desse crescimento e guarda, ao mesmo tempo, características singulares. Foi em um artigo publicado na revista Forum em 2014 que Ziyun Xu apresentou um estudo cientométrico 
sobre a produção de pesquisa em interpretação de conferências na China, segundo modelo já utilizado por outros autores, incluindo Daniel Gile.

Na China, o primeiro artigo sobre Estudos da Interpretação no país foi publicado em 1958, abordando a natureza da interpretação. Contudo, o desenvolvimento dos estudos na área demorou a acontecer, com apenas dois outros artigos registrados nos anos 1970. Xu (2014) atribui o fato à Revolução Cultural chinesa, década na qual apenas propaganda do Partido era publicada e em que o país permaneceu fechado para o restante do mundo, fazendo com que praticamente não fosse necessário recorrer à interpretação.

Foi somente após a instauração das políticas de liberalização, nos anos 1980, que as publicações voltaram: 55 na década de 1980 e 475 no ano de 2012. Ou seja, observou-se, nos anos pós-abertura, um forte crescimento tanto da prática quanto dos estudos em interpretação.

Grandes teorias e conceitos do Ocidente influenciaram as pesquisas na China, como os Modelos de Esforços de Gile, a pragmática cognitiva e a Teoria Interpretativa da Tradução (Théorie du Sens).

Desde o início dos anos 1990, foi constante o crescimento no número de publicações no país, com leve redução a partir de 2006. Contudo, a produção permanece constante devido ao grande número de universidades (106 até 2014) na China que passaram a oferecer programas de graduação em Tradução e Interpretação, sendo que grande parcela das mesmas passou a oferecer programas de mestrado na área.

Uma peculiaridade chinesa é o grande número de Community Colleges que passaram a oferecer cursos de interpretação para negócios (business interpreting) e, segundo $\mathrm{Xu}$ (2014), ainda que a política de publish or perish não seja aplicada no país, os formadores são estimulados por seus empregadores a produzir artigos, o que tem grande impacto no impulso observado nas revistas especializadas.

Entre as influências teóricas mais populares nos EI chineses estão teorias relacionadas a Cognição, seguidas por Língua e temas relacionados à Tradução. Mais especificamente, registra-se a presença da Teoria Interpretativa da Tradução, dos Modelos de Esforços de Daniel Gile e de conceitos oriundos de abordagens em comunicação intercultural e da psicologia cognitiva. 
Xu (2014) salienta que muito poucos artigos de natureza científica foram publicados antes de 2003, período no qual a produção assumia um caráter mais descritivo de conjuntos de dados. Contudo, ao se analisar o período entre 2003 e 2012 para determinar a presença de tendências, foram contabilizados quase três mil artigos publicados, o que nos dá uma dimensão da escala que os Estudos da Interpretação assumiram no país em anos recentes.

Naturalmente, a produção fica concentrada mais fortemente em regiões de maior contato intercultural, como as províncias costeiras da China, onde a demanda por serviços de interpretação também é maior. Mesmo após mais de uma década de forte expansão, a disciplina permanece forte no país, e a China já se estabeleceu como grande produtora de publicações na área de tradução e interpretação. A proporção de artigos de natureza empírica ainda é baixa (20\%) e a interpretação de conferências é o objeto de estudo privilegiado.

Para Gile (2010 apud XU, 2014), o que se observa na China é resultado do reconhecimento dos Estudos da Tradução e da Interpretação como uma disciplina independente (p. 185). A importância de se observar o caso chinês está justamente em colocarmos em perspectiva o tratamento que a área tem recebido no Ocidente e no Brasil, em particular. O caso chinês também evidencia como a pesquisa em tradução e interpretação pode ser impulsionada por motivações de natureza econômica e política e ao assumir um lócus privilegiado no âmbito acadêmico.

\section{Os Estudos da Interpretação no Brasil}

Em sua dissertação de mestrado, Denise Araújo (2017) oferece um panorama das formações de intérpretes existentes no Brasil. Ao longo de sua pesquisa, alguns dados são relevantes para se entender a evolução dos Estudos da Interpretação no país. É importante lembrarmos que, no Brasil, a profissão de intérprete começa a se organizar nas décadas de 1940 e 1950, com os primeiros congressos internacionais de maior envergadura. A fundação de cursos de formação no Brasil data do período entre o final dos anos 1960 e o início dos anos 1970. 
Apesar da diversidade de tipos de formação, já se formam intérpretes no Brasil há 50 anos, sendo que a profissionalização tomou impulso nas últimas duas décadas, acompanhada pelo surgimento de novos cursos. Nos anos 2010, um interesse renovado por pesquisas nos Estudos da Interpretação tem sido observado, com uma influência, não sem importância, das monografias produzidas por alunos oriundos de formações em nível de Especialização Lato Sensu, caso da PUC-Rio e da Estácio de Sá, ambas do Rio de Janeiro.

Já Branca Vianna (2015) concentra-se mais na atuação da AIIC com relação à formação de professores de interpretação, mas oferece alguns comentários sobre o desenvolvimento da área no Brasil. Cita a tese de Pagura (2010) como marco do início de um período de maior produção acadêmica nos Estudos da Interpretação brasileiros, ainda que no seio de departamentos de Linguística, Literatura ou Tradução. Vianna menciona ainda a escassez de cursos para intérpretes de qualquer natureza, sendo ainda mais reduzido o número de formações universitárias e em nível de pós-graduação. Considera o mercado sul-americano, de forma geral, como não tendo tradição de formação em interpretação, com implicações para a pesquisa na área. Por outro lado, em consequência dessa escassez, são muitas as possibilidades de estudo, num "campo aberto, inexplorado" (p. 17). A autora também menciona como contribuição importante para a produção acadêmica a obrigatoriedade de monografias de conclusão de curso em formações de pós-graduação lato sensu, como na PUC-Rio, a partir de 2009, e na Estácio de Sá, a partir de 2011, ambas com status de Especialização Lato Sensu, conforme mencionado acima. As monografias produzidas pelos alunos ilustram as diversas possibilidades de objetos de estudo nos EI e servem como meio de divulgação de conhecimento acadêmico e estímulo ao aprofundamento dos temas abordados, estando disponíveis nos bancos de monografias, dissertações e teses das respectivas instituições acadêmicas onde foram produzidas.

Outro artigo de abordagem cientométrica, desta vez com relação aos EI no Brasil, foi publicado por Patrizia Cavallo e Patrícia Reuillard na revista Letras $\mathcal{E}$ Letras, em 2016. Cavallo e Reuillard pesquisaram a publicação de teses, dissertações e artigos em revistas científicas relacionados aos Estudos 
da Interpretação no decênio de 2006 a 2016. As autoras constataram um número reduzido de produções até o ano de 2010, com incremento significativo no segundo quinquênio examinado, reforçando a afirmação de Pagura (2010) de que "no Brasil, a área é ainda incipiente, tendo sido pouquíssimas as pesquisas divulgadas" (p. 12).

As autoras verificaram que apenas sete dissertações de mestrado e três teses de doutorado foram realizadas no período analisado (2006-2016). Apesar de os números serem baixos quando comparados com outras disciplinas, como os Estudos da Tradução, Cavallo e Reuillard (2016) salientam que três trabalhos foram defendidos entre 2006 e 2010 e sete entre 2011 e 2015, o que poderia ser interpretado como um "aumento da conscientização sobre a importância de pesquisar a área de Estudos da Interpretação, bem como o início do reconhecimento da figura do intérprete" (p. 360).

Fica difícil sustentar essa hipótese diante de um volume tão reduzido de produção numa janela temporal limitada, sendo necessário acompanhar a evolução dos Estudos da Interpretação brasileiros no contexto de programas de pós-graduação por, pelo menos, mais uma década para se determinar se, de fato, o que afirmam as autoras se produziu.

Ao analisarem as publicações em periódicos, Cavallo e Reuillard (2016) consideraram cinco das principais revistas científicas da área de Tradução e Interpretação: Tradução em Revista (PUC-Rio), Belas Infiéis (UnB), Cadernos de Tradução (UFSC), Scientia Traductionis (UFSC) e TradTerm (USP). Entre os cinco periódicos analisados para o período de 2006 a 2016, apenas a TradTerm da USP apresentou mais de dois artigos publicados sobre interpretação, destoando das demais com um total de 15 artigos, dos quais 10 publicados em 2014, o que coincide com o ano seguinte ao primeiro Simpósio Brasileiro de Interpretação (SIMBI), organizado pela Universidade de São Paulo (USP). Além disso, 14 dos 15 artigos foram publicados entre 2011 e 2015.

É importante ressaltar que, no caso do periódico Tradução em Revista, da PUC-Rio, o período coberto pelo levantamento de Cavallo e Reuillard não incluiu os anos de 2017 e 2018, nos quais dois volumes (23 e 24) do periódico foram totalmente dedicados aos Estudos da Interpretação, totalizando 16 
artigos originais, 1 artigo traduzido e 1 entrevista. Vale ressaltar que a pesquisa de Cavallo e Reuillard (2016) desconsiderou as produções relacionadas à interpretação em língua de sinais. Assim, se aplicarmos a mesma metodologia, verificamos que a produção nos dois volumes mencionados do periódico Tradução em Revista incluía quatro artigos cobrindo temas ligados a interpretação em Libras-português, o que nos deixa com 12 artigos, uma tradução e uma entrevista. Ainda assim, pode-se dizer que o volume de contribuições foi acima da média, o que fica mais evidente se pensarmos que, inicialmente, apenas um volume havia sido planejado para cobrir o tema interpretação e foi a grande procura que levou à publicação do segundo volume.

As autoras mencionam ainda a falta de uniformidade da pesquisa em interpretação no Brasil, marcada por contribuições esparsas e muito diversificadas (CAVALLO; REUILLARD, 2016, p. 364), diversificação esta que pode ser observada nos dois números temáticos do periódico Tradução em Revista acima mencionados, abrangendo temas tão diversos como formação de intérpretes, historiografia da interpretação, interpretação em tribunais, interpretação em contexto religioso, questões de gênero em interpretação, para citar somente os trabalhos não relacionados à língua de sinais.

Cavallo e Reuillard (2016) concluem seu artigo afirmando que se verifica um interesse crescente no Brasil pelos Estudos da Interpretação, apesar do escasso número de formações em âmbito universitário e em nível de pós-graduação, mais propensos a formar novos pesquisadores e canalizar a produção e a publicação de pesquisas na área. Seria necessário um acompanhamento da presença do tema interpretação nos congressos da área de Tradução, como o Congresso Internacional da ABRAPT e Congresso Internacional de Tradutores, nos quais tem sido observada uma presença modesta mas constante dos Estudos da Interpretação, o Congresso da ABRATES, no qual a interpretação foi ganhando um espaço cada vez maior, contando também com a atuação de associações profissionais de intérpretes com salas exclusivas para temas relacionados à interpretação, caso da APIC. As autoras lembram que chegou a ser organizado um primeiro Simpósio Brasileiro de Interpretação (SIMBI) na USP, em 2013, conforme mencionado 
acima, com a intenção de torná-lo um evento permanente no calendário acadêmico, porém uma segunda edição nunca saiu do papel.

Para entendermos melhor o cenário delineado acima, é esclarecedor o artigo de Heloisa Gonçalves Barbosa, Caminhos e descaminhos dos estudos da tradução e interpretação no Brasil, de 2009. Barbosa inicia seu texto destacando que a área vivia, à época, uma crise e que nunca alcançou a posição de destaque imaginada por autores como Susan Bassnett. A situação era tal que autores como Anthony Pym e Mona Baker chegaram a se perguntar se existiria um local único e garantido para os Estudos da Tradução e da Interpretação e se os paradigmas da linguística e dos estudos culturais, presentes no seio da área, seriam complementares ou antagônicos. Tantos questionamentos, publicados às vésperas do ano 2000, sinalizavam, para Barbosa, a crise identitária vivida pelos Estudos da Tradução e da Interpretação.

Examinando os anais do X Encontro Nacional de Tradutores e IV Encontro Internacional de Pesquisadores em Tradução (ABRAPT), realizado em Ouro Preto em setembro de 2009, dez anos depois das palavras de Pym e Baker, Barbosa (2009) se deparou com uma área de estudos dividida em 22 subáreas difíceis de serem agrupadas em uma única área maior, indicando uma pulverização e não uma "concentração em torno de alguma tendência dominante" (p. 28). Para a autora, o caráter multidisciplinar e a falta de tendências dominantes estariam por trás dessa fragilidade.

Em termos institucionais, no âmbito brasileiro, Barbosa (2009) observa que foi feito um movimento pela inclusão da Tradução como subárea entre as rubricas da CAPES e do CNPq, contudo, a inclusão não foi obtida, denotando o status secundário atribuído ao campo da tradução, em suas diversas expressões. Uma consulta à tabela atual disponível no site da CAPES e datada de 31 de janeiro de 2017 revela que, dez anos depois da publicação do artigo de Barbosa (2009), a situação permanece a mesma. 


\subsubsection{0-2 Lingüística, Letras e Artes}

\subsubsection{0-7 Lingüística}

8.01.01.00-3 Teoria e Análise Lingüística

8.01.02.00-0 Fisiologia da Linguagem

8.01.03.00-6 Lingüística Histórica

8.01.04.00-2 Sociolingüística e Dialetologia

8.01.05.00-9 Psicolingüística

8.01.06.00-5 Lingüística Aplicada

\subsubsection{0-1 Letras}

8.02.01.00-8 Língua Portuguesa

8.02.02.00-4 Línguas Estrangeiras Modernas

8.02.03.00-0 Línguas Clássicas

8.02.04.00-7 Línguas Indígenas

8.02.05.00-3 Teoria Literária

8.02.06.00-0 Literatura Brasileira

8.02.07.00-6 Outras Literaturas Vernáculas

8.02.08.00-2 Literaturas Estrangeiras Modernas

8.02.09.00-9 Literaturas Clássicas

8.02.10.00-7 Literatura Comparada

(Fundação CAPES, 2019)

A autora menciona o esforço de acadêmicos da ANPOLL (Associação Nacional de Pós-Graduação e Pesquisa em Letras e Linguística) no biênio 2004-2006 para incluir a tradução como uma subárea entre as rubricas acima, chegando a apresentar uma nova proposta de tabela.

Vale ressaltar que, apesar de Heloisa Barbosa, ao longo de todo o seu artigo, falar em Estudos da Tradução e da Interpretação, em lugar algum da nova tabela proposta encontra-se o termo Interpretação, ou Estudos da Interpretação. Além disso, apesar de algumas referências a autores que abordaram tanto a tradução quanto a interpretação, como Susan Bassnett, 
não há, em seu artigo, nenhuma menção a autores consagrados da área de Estudos da Interpretação, como Barbara Moser-Mercer, Danica Seleskovitch, Daniel Gile ou Franz Pöchhacker, para citar apenas alguns dos nomes mais proeminentes na área, todos com volume significativo de produção científica publicada. Para a interpretação, isso é indicativo de que, se a área de Estudos da Tradução ainda luta por se fazer respeitar como uma subárea de Linguística, Letras e Artes, os Estudos da Interpretação, por sua vez, têm encontrado dificuldades para serem reconhecidos como uma subárea da Tradução.

Barbosa (2009) faz referência à grande expansão dos Estudos da Tradução e da Interpretação nos anos 1990 ao redor do mundo, como visto no início deste trabalho, com novos programas de mestrado e doutorado dedicados ao tema, maior número de publicações e eventos na área e novos cursos de formação. Porém, suas referências estão todas associadas aos Estudos da Tradução escrita que, apesar de terem sido precursores dos EI, não incluem os desenvolvimentos mais recentes em interpretação.

A autora nos lembra que "em nosso país, a totalidade dos cursos de formação de tradutores e intérpretes está vinculada a cursos de Letras" (Barbosa, 2009, p. 40). Quanto aos centros de produção científica, o primeiro programa de pós-graduação stricto sensu em Estudos da Tradução (PGET), que inclui em suas linhas de pesquisa a interpretação em suas diversas modalidades e contextos como objeto de estudo, foi criado em 2003, na Universidade Federal de Santa Catarina - UFSC (UFSC, 2019). Outro programa de pós-graduação stricto sensu em Tradução é o da Universidade de São Paulo - USP. A despeito da antiguidade do Departamento de Letras Modernas, no qual estão inseridos, os Estudos da Tradução "constituem ora projetos individuais, ora linhas de pesquisa, em boa parte dos programas credenciados na área de Letras, não apenas nos programas do Departamento de Letras Modernas", conforme publicado no site do próprio departamento (USP, 2019). Em 2011, foi inaugurado o Programa de Pós-Graduação em Tradução da Universidade de Brasília, o POSTRAD, em nível de mestrado. Mais recentemente, uma pós-graduação stricto sensu em Estudos da Tradução foi aberta na Universidade Federal do Ceará, iniciada em 2014, também em nível de mestrado. Com exceção do programa da UFSC, não há 
ênfase na produção de conteúdo sobre a interpretação nos programas citados.

Entre alguns autores-pesquisadores de relevância para os Estudos da Interpretação no Brasil, vinculados a instituições de ensino superior no país e com produção científica atual, destacam-se Reynaldo Pagura (USP), cuja tese de doutorado de 2010 marcou o início de uma fase de maior produção acadêmica em torno do objeto interpretação, Glória Regina Loreto Sampaio (PUC-SP), Luciana Ginezi (Uninove), Tito Lívio Romão Cruz (UFC), Teresa Dias Carneiro (PUC-Rio), Dennys Silva-Reis (UnB), Anelise Gondar (UERJ), Patrizia Cavallo (UFRGS), entre outros. As produções dos pesquisadores mencionados abrangem, em seu conjunto, diferentes modalidades e aspectos da interpretação. Outros pesquisadores-autores também contribuíram com o campo, porém, por não estarem vinculados a nenhuma instituição de ensino superior ou por terem contribuições pontuais, não foram aqui mencionados.

Até a presente data, não havia outros programas de pós-graduação na área. Aqueles que escolhem a interpretação como tema de dissertação de mestrado ou tese de doutorado e que não estejam na UFSC precisam se inserir em linhas de pesquisa que não abordam diretamente a interpretação.

Uma questão levantada por Barbosa (2009) diz respeito à formação dos docentes que atuam na formação de tradutores e intérpretes. Enquanto na tradução um número significativo de formadores possuem experiência profissional na área, na interpretação o cenário é um pouco diferente, com intérpretes atuantes no mercado sendo professores em cursos de diferentes categorias, universitários ou não, o que pode ser considerado fruto da influência da AIIC e suas diretrizes para cursos de formação de intérpretes, abordadas na primeira sessão deste artigo.

Heloisa Barbosa (2009) propõe que uma maior força política e visibilidade dos Estudos da Tradução e da Interpretação só poderia resultar de um esforço conjunto entre acadêmicos e profissionais liberais. Contudo, em sua opinião, existem divergências fortes em relação aos objetivos de cada uma dessas partes, estando os acadêmicos atrelados às exigências da CAPES em termos de produção científica e os profissionais, por sua vez, mais preocupados com o retorno financeiro ou material de sua atividade 
profissional, distanciados, em sua maioria, do universo acadêmico. A partir dessa constatação, a autora propõe que a pesquisa se volte mais para o ensino, num movimento de aproximação entre universidade e mercado de trabalho. Barbosa conclui enfatizando que a área está em crise, mas deixando no ar a dúvida se esta crise seriam "os estertores de morte ou a agonia do renascimento" (p. 42).

\section{Considerações finais}

Como podemos depreender a partir das informações aqui reunidas, a área de Estudos da Interpretação gozou de um crescimento significativo globalmente, em consonância com tendências de internacionalização das instituições e do mercado de trabalho.

Naturalmente, seu desenvolvimento está estreitamente associado ao desenvolvimento do mercado de trabalho em interpretação, sendo que este é mais forte nos países que concentram forte presença de organismos internacionais, como no caso dos países da Europa e da América do Norte, ou em comunidades multilíngues. Economias em franco desenvolvimento, como a chinesa, também oferecem terreno fértil para a produção acadêmica, impulsionada pelo crescimento do mercado, quando removidas as barreiras estatais e institucionais e como resultado de investimentos na priorização do setor, como se viu na China.

Infelizmente, tanto em termos de economia quanto em termos de estruturação institucional, o Brasil não oferece um cenário muito promissor para a expansão da área de Estudos da Interpretação, ainda que um aumento do interesse por pesquisas na área de EI possa ser verificado nos últimos anos, como atestam os resultados de investigações como a realizada por Cavallo e Reuillard (2016) e os conteúdos de publicações na área.

Uma parte desse interesse renovado pela interpretação decorreu, certamente, da grande midiatização pela qual a profissão de intérprete passou entre 2012 e 2016, devido à presença de grandes eventos internacionais no país (Rio+20, Jornada Mundial da Juventude, Copa do Mundo, Olimpíadas). Contudo, observa-se também uma tendência a abordar novas temáticas em interpretação, com um crescimento visível de 
trabalhos de cunho historiográfico e produções que contemplam questões socioculturais.

A realização do XIII Encontro Nacional de Tradutores / VII Encontro Internacional de Tradutores, de 7 a 11 de outubro de 2019, permitiu que fossem mais uma vez observadas as tendências em termos de pesquisas na área, mas podemos, desde já, ponderar o seguinte: a diversificação de temáticas dentro da área de interpretação e a consequente criação de subáreas de conhecimento pode gerar uma fragilização dos Estudos da Interpretação antes mesmo de sua consolidação no país. Se essa mesma dúvida assombra acadêmicos europeus, o que dizer do campo brasileiro, cuja produção é ainda incipiente se comparada à europeia? É preciso que pensemos cuidadosamente no fortalecimento dos EI, mesmo que sob a égide dos ET, para que não presenciemos uma morte prematura da área no Brasil.

Para citar o exemplo do XIII ENTRAD, mencionado acima, observamos dois pontos interessantes: 1) a primeira mesa redonda do evento, no dia 07 de outubro, teve como tema a Formação de intérpretes no Brasil, EUA e Chile, sinal do interesse por trocas de experiência docente nos diversos centros de ensino de intepretação em âmbito universitário; 2) dos vinte e nove simpósios propostos, cinco abordavam o tema interpretação, sendo um pelo viés da didática da formação de tradutores e intérpretes, um pelo viés da relação entre mediação cultural e interpretação, outro mais geral, abordando as múltiplas possibilidades nos Estudos da Interpretação, um sobre tradução e interpretação em língua de sinais e, por fim, um sobre tradução e interpretação públicas. Apesar da aparente diversidade de temas, o que se observou foi um esvaziamento, com poucas propostas de comunicação sendo apresentadas para cada simpósio, o que levou à uma reorganização de salas, de maneira a abrigar, por vezes, dois simpósios afins em uma mesma sala e horário. Ainda assim, foi baixa a participação em termos de público. Para termos uma ideia do volume de produções reunidas no congresso na área temática de Estudos da Interpretação (simpósios 7.1 e 7.2), foram inscritas 16 comunicações, sendo duas sobre interpretação em língua de sinais, uma sobre anotações para consecutiva, uma sobre interpretação médica, uma sobre cultura e trabalho do intérprete, uma sobre mulheres negras na história da tradução do Brasil, uma sobre autoavaliação 
no ensino de interpretação, uma sobre o papel da Associação Profissional de Intérpretes de Conferência e sua história, uma sobre enfoques cognitivos na tradução e na interpretação, uma sobre a história do curso de formação de intérpretes da PUC-Rio, uma sobre o processo de interpretação e a influência do conhecimento de domínio, uma sobre os intérpretes do Serviço de Proteção aos Índios, uma sobre fotografias históricas de intérpretes, uma sobre a tarefa de interpretar, uma sobre práticas e didáticas de interpretação e mediações linguístico-culturais, uma sobre o uso de videogame como ferramenta de ensino. Podemos reunir as contribuições acima nas categorias seguintes: língua de sinais (2), técnica de interpretação (1), historiografia (5), processo (3), ensino (3), modalidade (1), teoria (1). O perfil das comunicações reflete, conforme disseram Cavallo e Reuillard (2016) um caráter esparso e diversificado, porém, com um interesse significativo pela historiografia da interpretação no Brasil.

O que observamos até o momento não difere do que foi mencionado por autores como Gile e Pöchhacker quando se referiam ao contexto europeu. Ou seja, há um número limitado de pesquisadores na área, muitos são intérpretes atuantes e têm como prioridade o sustento a partir da profissão de intérprete e não de pesquisador.

Além disso, no Brasil ainda verificamos um status institucional delicado para os Estudos da Tradução, que continuam, de forma geral, a brigar por um espaço mais definido dentro das áreas de Letras, Linguística ou Literatura, tornando ainda mais frágil a situação da subárea de EI, cuja presença institucional é praticamente nula.

A despeito de tantos obstáculos, há espaço para iniciativas de integração e reforço da área. Em particular, é o caso do I Congresso sobre Estudos da Interpretação, organizado em conjunto com o II Colóquio de Interpretação de Línguas de Sinais em contextos comunitários: saúde, educação \& justiça, em Brasília, nos dias 27 a 30 de agosto de 2019. Os eventos são organizados pelas seguintes universidades: Universidade de Brasília (UnB), Universidade Federal de Goiás (UFG), Universidade Federal de Minas Gerais (UFMG) e Universidade Federal de Santa Catarina (UFSC), contando com membros da Pontifícia Universidade Católica do Rio de Janeiro (PUC-Rio) na comissão científica. 
Segundo texto divulgado no site do evento, seus objetivos incluem:

(...) permitir aos pesquisadores, professores, alunos e interessados na área a reflexão sobre o lugar dos Estudos da Interpretação, evidenciando as demandas contemporâneas, mas também das práticas profissionais e da formação de intérpretes. Sobretudo a aproximação dos Estudos da Interpretação das línguas de sinais e das línguas orais que é uma tendência importante para a sua consolidação no Brasil. Contando, dessa forma, com um público especializado na área dos Estudos da Interpretação de todos os lugares do Brasil (I CONEI \& II SILSC, 2019).

Iniciativas como esta podem contribuir para uma maior integração das subáreas dos Estudos da Interpretação, porém, é preciso ter em mente que a interpretação de conferências não goza do mesmo status da interpretação em libras, regulamentada por lei sancionada em 2010, o que ocasionou um desenvolvimento diferenciado para o setor de interpretação libras-português, incluindo a abertura de cursos de formação de intérpretes de libras em nível universitário, com consequente geração de pesquisas e publicações. A grande diferença institucional entre essa modalidade de interpretação e a interpretação de conferências é justamente o motivo pelo qual este trabalho não inclui a modalidade Libras-português em suas análises.

Finalmente, apesar da crise econômica pela qual passa o país e apesar da imutabilidade do contexto institucional e acadêmico relativo à interpretação, ainda existe interesse pelos EI, e despontam iniciativas para aprofundar reflexões a seu respeito e, quem sabe, garantir sua evolução no cenário brasileiro.

Este trabalho, mesmo não esgotando o tema, pretendeu trazer um olhar sobre a evolução dos EI no Brasil em perspectiva com os acontecimentos ao redor do mundo, para que os dados locais possam ser examinados a partir de uma visão mais ampla. Estudos como o apresentado por Cavallo e Reuillard (2016) são importantes para se observar o desenvolvimento do setor e representam uma possibilidade concreta de novas pesquisas, assim como os estudos de gênero, historiográficos e 
culturais, que contribuem para a formação de uma identidade brasileira em interpretação.

\section{Referências}

I CONEI \& II SILSC. Página de apresentação do I Congresso sobre Estudos da Interpretação e II Colóquio sobre Interpretação em Línguas de Sinais em Contextos Comunitários: saúde, educação \& justiça. Disponível em: http://congressodeinterpretacao.com.br/apresentacao/. Acesso em: 08 jul. 2019.

ARAUJO, Denise de V. Os cursos de formação de intérpretes no Brasil e as melhores práticas da Associação Internacional de Intérpretes de Conferência: um caminho para a profissionalização. Dissertação de mestrado - Pontifícia Universidade Católica do Rio de Janeiro, Departamento de Letras, 2017.

ASSIS, Roberto C. et al. (Org.). Caderno de Resumos. Encontro Nacional de Tradutores, João Pessoa, UFPB, 2019.

BARBOSA, Heloisa. Caminhos e Descaminhos dos Estudos da Tradução e da Interpretação no Brasil. In: Revista Trama, vol. 5, n. 9, 2009.

BASSNETT, Susan. The origins and develpment of Translation Studies. In: . Translation. London/New York: Routledge, 2014, 16-36.

CAVALLO, Patrizia e REULLIARD, Patrícia C. R. Estudos da Interpretação: tendências atuais da pesquisa brasileira. In: Letras \& Letras. Uberlândia, vol. 31/1, jan/jun 2016, p. 353-368.

FUNDAÇÃO CAPES. Tabela de Áreas de Conhecimento / Avaliação. Disponível em: https://www.capes.gov.br/pt/avaliacao/instrumentos-deapoio/tabela-de-areas-do-conhecimento-avaliacao. Acesso em: 07 jul. 2019. GILE, Daniel. The History of Research into Conference Interpreting: a Scientometric Approach. Target, v. 12:2, p. 297-321, 2000.

LEFEVERE, André; BASSNETT, Susan. Introduction: Proust's Grandmother and the Thousand and One Nights: The 'Cultural Turn' in Translation Studies. In: BASSNETT, Susan; LEFEVERE, André (Eds.). Translation, History and Culture. London/NY: Pinter, 1990. 
PAGURA, Reynaldo J. A interpretação de conferências no Brasil: história de sua prática profissional e a formação de intérpretes brasileiros. Tese apresentada ao Programa de Pós-Graduação em Estudos Linguísticos e Literários do Inglês, do Departamento de Letras Modernas, da Faculdade de Filosofia, Letras e Ciências Humanas da Universidade de São Paulo, para obtenção do título de doutor em Letras. 2010.

PÖCHHACKER, Franz. Introducing Interpreting Studies. Routledge, London and New York, 2004.

SNELL-HORNBY, Mary. Translation Studies - The Emergence of a discipline. In:___ The Turns of Translation Studies: New Paradigms or Shifting Viewpoints? Amsterdam/Philadelphia: John Benjamins, 2006.

UFSC. Página do Programa de Pós-Graduação em Estudos da Tradução, Apresentação. Disponível em: http://ppget.posgrad.ufsc.br/historico/. Acesso em: 07 jul. 2019.

USP. Página institucional do Departamento de Letras Modernas, Histórico da Tradução na USP. Disponível em: http://dlm.fflch.usp.br/traducao/850. Acesso em: 07 jul. 2019.

VIANNA, Branca. A atuação do Comitê de Formação e Atualização Profissional da AIIC no novo panorama de ensino e pesquisa no Brasil. Apresentação no VI Congresso Internacional de Tradução e Interpretação da ABRATES, 2015, e na Jornada de Pesquisa Contemporânea em Tradução e Interpretação, USP CITRAT, 2015. Disponível em: https://interpret2b.com/cms/uploads/publicacoes/publicacao_8/a\%20atuaca o\%20do\%20Comite\%20de\%20Formacao $\% 20 \mathrm{e} \% 20$ Atualizacao $\% 20$ Profission al\%20da\%20AIIC\%20no\%20novo\%20panorama\%20de\%20ensino \%20e\%20 pesquisa\%20no\%20Brasil_Branca\%20Vianna.pdf. Acesso em: 04/07/2019. XU, Ziyun. Chinese Interpreting Studies: Genesis of a Discipline. In: FORUM, vol. 12, n. 2, p. 159-190, 2014.

\section{Resumo}

Os Estudos da Interpretação (EI) evoluíram ao longo das últimas décadas. Sua evolução, contudo, é marcada por limitações, como a escassez de pesquisadores, a falta de institucionalização e outros. O padrão de 
desenvolvimento dos EI observado na Europa e nos Estados Unidos não é o mesmo que se observa em países do Oriente ou do hemisfério sul ocidental, como no Brasil. Entretanto, comparar a evolução histórica dos EI nessas diferentes regiões nos ajuda a ter maior clareza sobre os padrões da área em geral e as necessidades específicas de cada região. Uma revisão bibliográfica e uma abordagem comparativa foram usadas para possibilitar uma melhor compreensão da atual situação dos EI no Brasil.

Palavras-chave: Estudos da Interpretação; História; Pesquisa.

\begin{abstract}
Interpreting Studies (IS) have evolved over the last decades. Their evolution, however, is marked by shortcomings such as the small number of dedicated researchers, the lack of institutionalization, and others. The pattern of IS development seen in Europe and in the United States is not the same found in Eastern countries and countries from the Western Southern Hemisphere, like Brazil. Nevertheless, comparing the historical evolution of IS in these different regions may shed some light on the general patterns in the field and on the specific needs of each region. A literature review and a comparative approach were used to enable a better understanding of the current position of IS in Brazil.
\end{abstract}

Keywords: Interpreting Studies; History; Research. 